04

\title{
Влияние нестехиометрии на период решетки кубического карбида ванадия $\mathrm{VC}_{y}$
}

\author{
(C) А.С. Курлов, А.И. Гусев \\ Институт химии твердого тела УрО РАН, \\ Екатеринбург, Россия \\ ฯ E-mail: gusev@ihim.uran.ru
}

(Поступила в Редакцию 6 февраля 2017 г.)

Изучено влияние нестехиометрии на период решетки кубического карбида ванадия $\mathrm{VC}_{y}$ $(0.65<y<0.875)$. Установлено, что упорядочение карбида ванадия $\mathrm{VC}_{y}$ с образованием сверхструктур $\mathrm{V}_{6} \mathrm{C}_{5}$ и $\mathrm{V}_{8} \mathrm{C}_{7}$ приводит к росту периода базисной кристаллической решетки по сравнению с неупорядоченным карбидом. С учетом изменения периода решетки обсуждается вопрос о направлении статических смещений атомов вблизи вакансии.

Исследование выполнено в ИХТТ УрО РАН за счет гранта Российского научного фонда (проект РНФ № 14-23-00025).

DOI: $10.21883 /$ FTT.2017.08.44748.30

\section{1. Введение}

Карбид ванадия принадлежит семейству карбидов переходных металлов IV-VI групп $(M=\mathrm{Ti}, \mathrm{Zr}, \mathrm{Hf}, \mathrm{V}$, $\mathrm{Nb}, \mathrm{Ta})$, являющихся одними из самых твердых и тугоплавких соединений. В системе ванадий-углерод $\mathrm{V}-\mathrm{C}$ наибольший интерес представляет кубический карбид ванадия $\mathrm{VC}_{y}$. Карбид ванадия $\mathrm{VC}_{y}$ широко используется в металлургической промышленности в качестве легирующей добавки для упрочнения сталей [1-3], а также как ингибитор роста зерен WC в субмикро- и нанокристаллических твердых сплавах WC-Co [4-8], которые применяются для производства самого высококачественного бурильного и режущего инструмента. Другая перспективная область применения карбида ванадия - использование как катализатора для восстановления кислорода и окисления спиртов [9-12].

Влияние нестехиометрии на период базисной кристаллической решетки нестехиометрических карбидов $\mathrm{MC}_{y}\left(\mathrm{MC}_{y \square 1-y}\right)$ со структурой $B 1$ изучали многие авторы. Согласно результатам исследований, по мере уменьшения содержания атомов углерода С или, что то же самое, с ростом концентрации структурных вакансий $\square$ наблюдается нелинейное уменьшение периода решетки $a_{B 1}$ этих соединений.

Неупорядоченный кубический карбид ванадия $\mathrm{VC}_{y}$ (пространственная группа (пр. гр.) $F m \overline{3} m$ ) имеет широкую область гомогенности от $\mathrm{VC}_{0.65}$ до $\mathrm{VC}_{0.875} \mathrm{c}$ уникальным положением верхней границы, существенно удаленной от стехиометрического состава $\mathrm{MC}_{1.0}[13,14]$. Других неупорядоченных кубических карбидов с таким положением верхней границы области гомогенности нет. В области гомогенности неупорядоченного кубического карбида $\mathrm{VC}_{y}$ в результате отжига при температуре ниже $1360 \mathrm{~K}$ могут образовываться две упорядоченные фазы $\mathrm{V}_{6} \mathrm{C}_{5}$ и $\mathrm{V}_{8} \mathrm{C}_{7}$ [13-15]. Особенно легко образуется кубическая (пр. гр. $P 4_{3} 32$ ) упорядоченная фаза $\mathrm{V}_{8} \mathrm{C}_{7}$.

Ранее уже изучалось изменение периода кристаллической решетки в зависимости от состава нестехиометрического кубического карбида ванадия $\mathrm{VC}_{y}$. Однако в большинстве исследований не было определено, каково структурное состояние изученных образцов - неупорядоченное или упорядоченное.

Упорядочение влияет на период базисной кристаллической решетки карбида ванадия, приводя к его росту $[13,14,16-21]$. Впервые увеличение периода базисной решетки при превращении $\mathrm{VC}_{0.875} \rightarrow \mathrm{V}_{8} \mathrm{C}_{7}$ было зафиксировано в работе [16] при изучении упорядочения нестехиометрического карбида ванадия. Согласно [16], при комнатной температуре период базисной решетки закаленного неупорядоченного карбида $\mathrm{VC}_{0.875}$ составлял $0.41662 \mathrm{~nm}$, а упорядоченного карбида этого же состава - $0.41667 \mathrm{~nm}$ (или $0.83334 \mathrm{~nm}$ для кубической сверхструктуры $\mathrm{V}_{8} \mathrm{C}_{7}$ с удвоенным периодом решетки). Это хорошо согласуется со скачкообразным изменением периода базисной решетки карбида ванадия от 0.4202 до $0.4200 \mathrm{~nm}$ в результате разупорядочения фазы $\mathrm{V}_{8} \mathrm{C}_{7}$ при нагреве выше температуры превращения порядок-беспорядок $T_{\text {trans }}=1413 \pm 10 \mathrm{~K}$. Этот эффект был обнаружен при высокотемпературном рентгеновском исследовании [16]. В [20] показано, что при комнатной температуре период базисной решетки упорядоченной фазы $\mathrm{V}_{6} \mathrm{C}_{5}$ во всей области гомогенности больше, чем период $a_{B 1}$ неупорядоченного карбида $\mathrm{VC}_{y}$.

Работ по определению периода решетки именно неупорядоченного карбида ванадия мало. Это работы, в которых карбид ванадия был синтезирован при высоких (более $1500 \mathrm{~K}$ ) температурах с последующей закалкой, что обеспечивало получение неупорядоченного карбида, или работы, где целенаправленно получали кар- 
бид $\mathrm{VC}_{y}$ как в неупорядоченном, так и в упорядоченном состояниях

В работе [22] однофазные образцы кубического карбида ванадия $\mathrm{VC}_{y}(y=0.762,0.782,0.808,0.825$, $0.869)$ были синтезированы газовой карбидизацией (gas carburization) волокон ванадия диаметром $\sim 0.25 \mathrm{~mm}$ в метане $\mathrm{CH}_{4}$ при $\sim 1780 \mathrm{~K}$ в течение $8 \mathrm{~h}$. Дополнительно карбид $\mathrm{VC}_{0.876}$ был получен горячим прессованием смеси порошков ванадия и графита в вакууме при температуре около $2200 \mathrm{~K}$ и давлении прессования $\sim 1.6 \mathrm{MPa} \mathrm{в}$ течение $30 \mathrm{~min}$.

В работе [23] образцы кубического карбида ванадия $\mathrm{VC}_{y}(y=0.72,0.74,0.76,0.79,0.84$ и 0.88$)$ были синтезированы карботермическим восстановлением оксида $\mathrm{V}_{2} \mathrm{O}_{3}$ газовой сажей при температуре $\sim 2300 \mathrm{~K}$ в течение $15 \mathrm{~h}$. Согласно предшествующей работе [24], синтезированные образцы от $\mathrm{VC}_{0.72}$ до $\mathrm{VC}_{0.79}$ содержали до 1.0 at.\% примесного кислорода, в образцах $\mathrm{VC}_{0.84}$ и $\mathrm{VC}_{0.88}$ содержание примесного кислорода было $\sim 0.3$ at. $\%$.

В работах [17-21] образцы неупорядоченного кубического карбида ванадия $\mathrm{VC}_{y}(y=0.66,0.79,0.83 .0 .87)$ были получены горячим прессованием смеси порошков карбида ванадия $\mathrm{VC}_{0.87}$ и металлического ванадия в атмосфере аргона $\mathrm{Ar}$ при температуре около $2200 \mathrm{~K}$ и давлении прессования $35 \mathrm{MPa}$ в течение $30 \mathrm{~min}$. Содержание примесного кислорода в полученных образцах составляло от 0.3 до 0.6 at.\%.

Данная работа посвящена определению зависимости периода решетки от состава неупорядоченного кубического (пр. гр. $F m \overline{3} m$ ) карбида ванадия $\mathrm{VC}_{y}$ с разной нестехиометрией в пределах его области гомогенности от $\mathrm{VC}_{0.65}$ до $\mathrm{VC}_{0.875}$.

\section{2. Образцы и экспериментальные методы}

Образцы нестехиометрического кубического (пр. гр. $F m \overline{3} m$ ) карбида ванадия $\mathrm{VC}_{y}$ с разным составом $(y=0.68,0.71,0.73,0.76,0.81,0.85$ и 0.87$)$ в пределах его области гомогенности были синтезированы твердофазным вакуумным спеканием смеси порошков ванадия и черной газовой сажи МТ-900. Перед приготовлением шихты сажу для удаления влаги сушили в течение $2 \mathrm{~h}$ при температуре $470-500 \mathrm{~K}$ в разряженной атмосфере с остаточным давлением $10^{3} \mathrm{~Pa}$. Тщательно перемешанные порошки ванадия и просушенной сажи, взятые в требуемых пропорциях с учетом потери углерода при синтезе, прессовали под давлением $200 \mathrm{MPa}$. Синтез проводили в вакуумной высокотемпературной печи LF-22-2000 (Centorr/Vacuum Industries) при температуре от 1573 до $2073 \mathrm{~K}$ в течение $5 \mathrm{~h}$.

Кристаллическую структуру, фазовый состав и параметры решетки синтезированных образцов $\mathrm{VC}_{y}$ определяли методом рентгеновской дифракции на автодифрактометре Shimadzu XRD-7000 с геометрией съемки плоского образца по Бреггу-Брентано в интервале углов $2 \theta$ от 10 до $140^{\circ}$ с пошаговым сканированием $\Delta(2 \theta)=0.03^{\circ}$ и временем экспозиции $2 \mathrm{sec}$ в точке в излучении $\mathrm{Cu} K_{\alpha_{1,2}}$. Рентгенограммы анализировались с помощью программного пакета X'Pert HighScore Plus [25]. Кристаллическую структуру упорядоченного карбида $\mathrm{V}_{8} \mathrm{C}_{7}$ дополнительно исследовали методом TOF-нейтронографии (time-of-flight - по времени пролета).

Морфологию и размер частиц синтезированных образцов $\mathrm{VC}_{\text {y }}$ изучали с помощью сканирующего электронного микроскопа JEOL JSM 6390 LA.

Химический анализ образцов $\mathrm{VC}_{y}$ на общее содержание углерода $\mathrm{C}_{\text {total }}$ и содержание свободного углерода $\mathrm{C}_{\text {free }}$ проводили с помощью анализатора МЕТАВАК CS-30. Содержание примесных элементов определяли на масс-спектрометре Perkin Elmer SCIEX-ELAN 9000 и энергодисперсионным рентгеновским (EDX) анализом на микроскопе JEOL JSM 6390 LA с анализатором JED 2300.

\section{3. Обсуждение результатов}

На рис. 1 показаны рентгенограммы синтезированных карбидов ванадия $\mathrm{VC}_{y}$ с разным относительным содержанием углерода $y$ в интервале от 0.68 до 0.87 . О высокой степени гомогенности синтезированных карбидов ванадия $\mathrm{VC}_{y}$ свидетельствует расщепление $\mathrm{Cu} K_{\alpha_{1,2}}$-дублетов, которое наблюдается уже для линии (200) в области малых углов $2 \theta \approx 43^{\circ}$ (см. правую вставку на рис. 1 ). Образцы $\mathrm{VC}_{y}(y=0.68,0.71,0.73,0.76,0.81,0.85)$ содержат только неупорядоченный кубический (пр. гр. $F m \overline{3} m$ ) карбид ванадия. Уточнение дифракционных данных образца $\mathrm{VC}_{0.87}$ показало, что даже после закалки от температуры $\sim 2000 \mathrm{~K}$ этот образец содержит $\sim 82 \mathrm{wt} . \%$ упорядоченной кубической (пр. гр. $P 4_{3} 32$ ) фазы $\mathrm{V}_{8} \mathrm{C}_{7}$ $\left(\mathrm{VC}_{0.875}\right)$ и $\sim 18 \mathrm{wt} . \%$ неупорядоченного карбида $\mathrm{VC}_{0.87}$ с периодом $0.4162 \mathrm{~nm}$ (см. рис. 1, левая вставка). Период решетки $a_{\text {ord }}$ Упорядоченной фазы $\mathrm{V}_{8} \mathrm{C}_{7}$ равен $0.8336 \mathrm{~nm}$. Период решетки базисной неупорядоченной кубической фазы равен половине периода решетки $a_{\text {ord }}$ упорядоченной фазы, т.е. $a_{\text {ord }} / 2=0.4168 \mathrm{~nm}$, и больше периода $a_{B 1}=0.4162 \mathrm{~nm}$ неупорядоченного карбида $\mathrm{VC}_{0.875}$. Это согласуется с данными $[16,19]$ о скачкообразном увеличении периода базисной решетки карбида ванадия при превращении беспорядок-порядок $\mathrm{VC}_{0.875}-\mathrm{V}_{8} \mathrm{C}_{7}$.

Изменение периода решетки $a_{B 1}(y)$ синтезированного карбида ванадия в области гомогенности кубической (пр. гр. $F m \overline{3} m$ ) неупорядоченной фазы $\mathrm{VC}_{y}$ показано на рис. 2. Для сравнения приведены данные предшествующих исследований $[18,20,22,23]$. В пределах точности экспериментальных результатов все концентрационные зависимости периода являются квадратичными функциями от содержания атомов углерода $y$, т.е. $\sim a_{B 1}(y)=a_{0}+a_{1 y}+a_{2} y^{2}$. Данные [23] явно занижены из-за большого содержания примесного кислоро- 


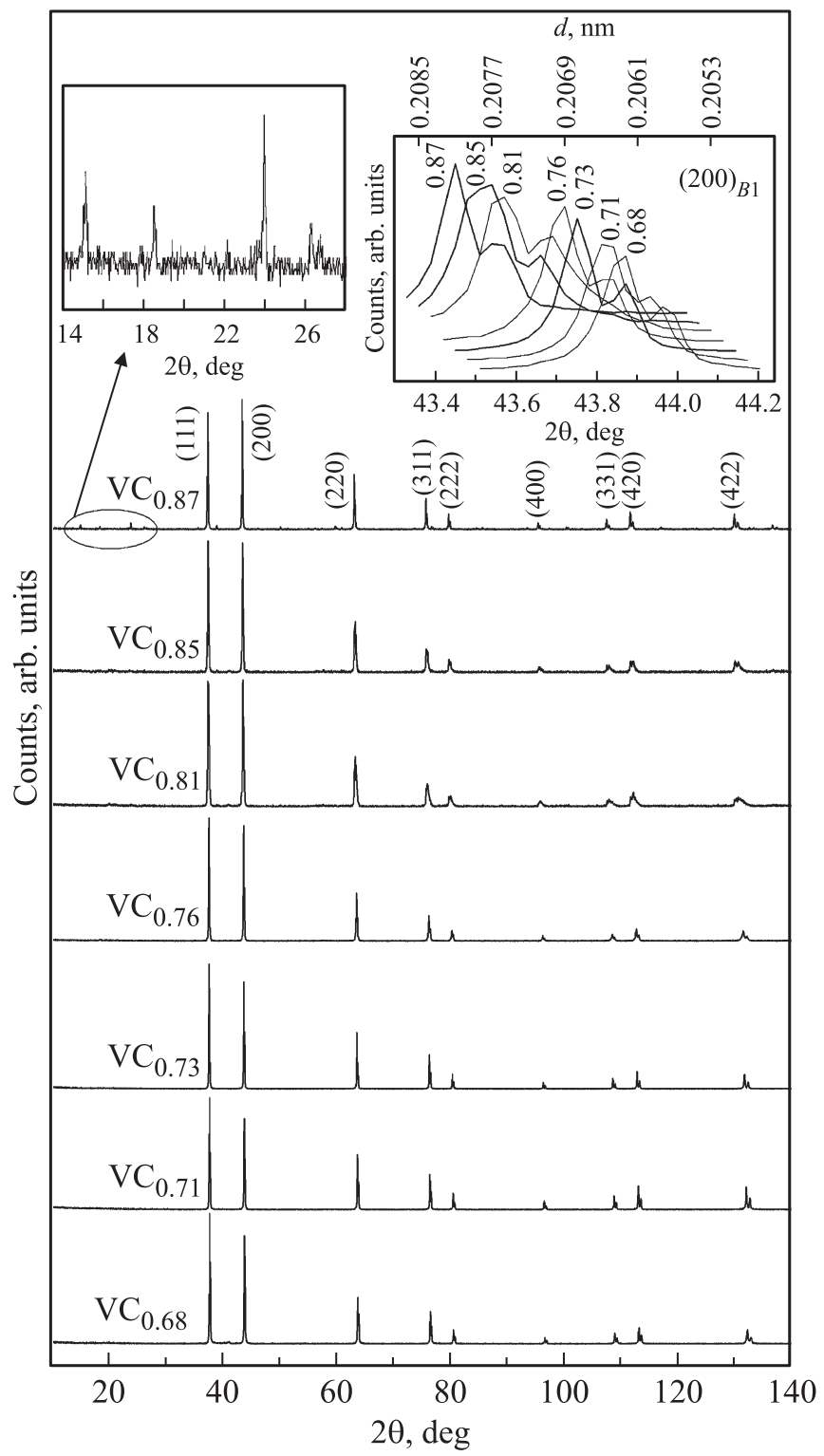

Рис. 1. Рентгенограммы синтезированных образцов $\mathrm{VC}_{y}$. На вставке справа показано расщепление дифракционных отражений $(200)_{B 1}$ синтезированных карбидов $\mathrm{VC}_{y}$ и их смещение в область меньших углов $2 \theta$ (и больших межплоскостных расстояний $d$ ) при увеличении содержания углерода. На левой вставке показан участок рентгенограммы карбида $\mathrm{VC}_{0.87} \mathrm{c}$ дифракционными отражениями, характерными для упорядоченной фазы $\mathrm{V}_{8} \mathrm{C}_{7}$. Все рентгенограммы записаны в излучении $\mathrm{Cu} K_{\alpha_{1,2}}$.

да в неметаллической подрешетке карбидов, особенно в области от $\mathrm{VC}_{0.72}$ до $\mathrm{VC}_{0.79}$. Наибольшее согласование данных разных работ наблюдается для $\mathrm{VC}_{y}$ в области $y=0.80-0.87$. Период решетки синтезированного в данной работе неупорядоченного карбида ванадия $\mathrm{VC}_{y}$ с кубической структурой $B 1$ описывается функцией $a_{B 1}(y)=a_{0}+a_{1 y}+a_{2} y^{2}$ с параметрами $a_{0}=0.38954, a_{1}=0.04550$ и $a_{2}=-0.01693 \mathrm{~nm}$.
В нестехиометрических карбидах с базисной структурой $B 1$ каждый атом металла находится в ближайшем окружении шести узлов неметаллической подрешетки, которые могут быть заняты атомами углерода или вакантны. Это дает возможность представить кристалл со структурой $B 1$ как совокупность кластеров в форме многогранников Дирихле-Вороного, т.е. искаженной ячейки Вигнера-Зейтца (в структуре $B 1$ ячейкой Вигнера-Зейтца является ромбододекаэдр). Каждый кластер включает в себя атом металла, расположенный в центре, и шесть узлов углеродной подрешетки (рис. 3), которые могут быть заняты атомами углерода или вакантны. Такие кластеры заполняют весь объем кристалла, обеспечивают континуальность среды, учитывают все узлы кристаллической решетки и позволяют описать изменение объема или периода элементарной

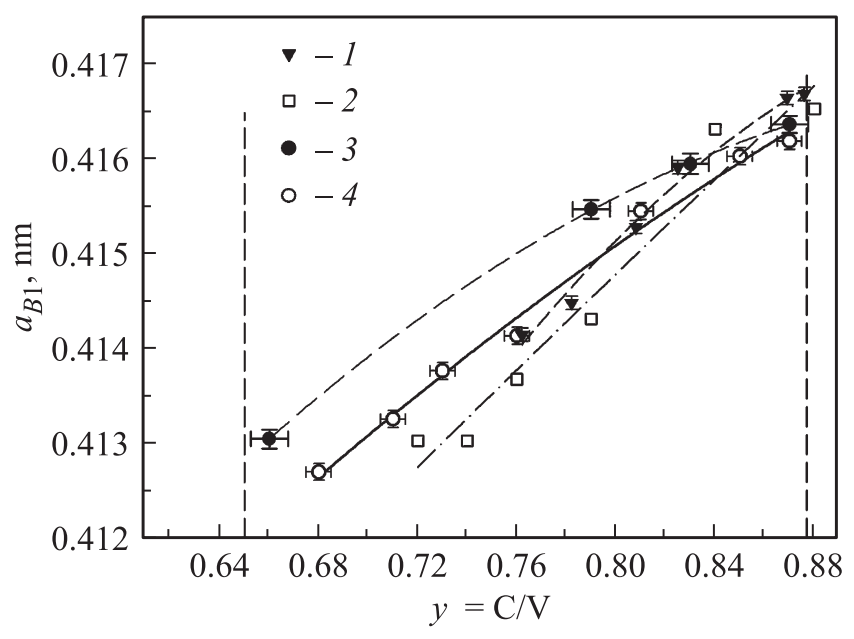

Рис. 2. Период решетки $a_{B 1}(y)$ карбида ванадия в области гомогенности кубической (пр. гр. $F m \overline{3} m$ ) неупорядоченной фазы $\mathrm{VC}_{y}$ по данным разных работ: 1 - [22], $2-[23]$, 3 - [18,20], 4 - данные настоящей работы. Границы области гомогенности фазы $\mathrm{VC}_{y}$ показаны вертикальными пунктирными линиями.

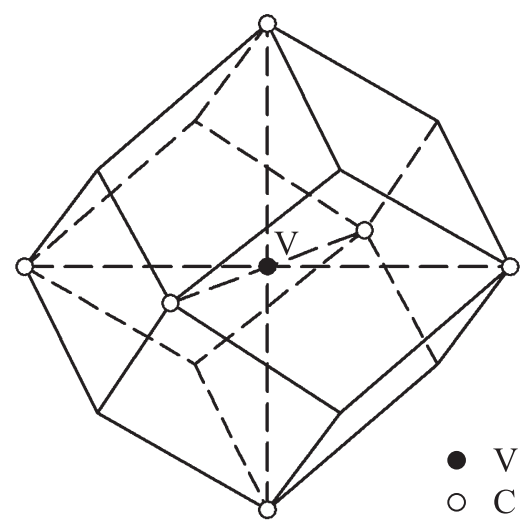

Рис. 3. Кластерная фигура в виде ромбододекаэдра, используемая для описания кристаллической решетки нестехиометрического карбида ванадия $\mathrm{VC}_{y}$ с базисной кубической структурой типа $B 1$. 
ячейки карбида $\mathrm{VC}_{y}$ как функцию состава $y$ и степени дальнего порядка $\eta$.

В первом приближении будем полагать, что объем кластера $V_{m}$ зависит только от числа вакансий $m$ в нем. В этом случае объем кристалла $V$ можно представить в виде

$$
V=N \sum_{m=0}^{6} \lambda_{m} P_{m}(y, \eta) V_{m},
$$

где $P_{m}(y, \eta)$ - вероятность образования в кристалле кластера с числом вакансий, равным $m ; \eta$ - параметр дальнего порядка; $\lambda_{m}=C_{6}^{m}-$ мультиплетность $m$-конфигурации кластера; $N$ - число узлов металлической подрешетки. С другой стороны, объем неупорядоченного карбида можно представить через период решетки $a_{B 1}(y)=a_{0}+a_{1} y+a_{2} y^{2}$ как $V=(N / 4) a_{B 1}^{3}(y)$. $\mathrm{C}$ учетом этого уравнение (1) для неупорядоченного карбида примет вид

$$
\sum_{m=0}^{6} \lambda_{m} P_{m}(y, 0) V_{m}=\frac{\left(a_{0}+a_{1} y+a_{2} y^{2}\right)^{3}}{4}
$$

где $P_{m}(y, 0)=(1-y)^{m} y^{(6-m)}-$ вероятность образования в неупорядоченном карбиде кластера, включающего $m$ вакансий. Решением уравнения (2) является выражение для объема кластера:

$$
V_{m}=\frac{1}{4} \sum_{k=m}^{6} A_{6-k} \frac{k !(6-m) !}{6 !(k-m) !}
$$

где $A_{6-k}-$ коэффициенты при $y^{k}$ в правой части уравнения (2).

Вклад каждого типа кластера в общий объем кристалла пропорционален вероятности его образования $P_{m}$. Для равновесных условий вероятность $P_{m}(y, \eta)$ существования кластера, содержащего $m$ вакансий, в упорядоченной фазе типа $M_{2 t} \mathrm{C}_{2 t-1}$ с любой степенью дальнего порядка можно представить $[13,14]$ в виде

$$
\begin{aligned}
P_{m, t}(y, \eta)= & \frac{1}{\Phi} \sum_{j} \frac{g_{f}}{C_{6}^{v(t, f)}} \sum_{\nu=0}^{v(t, f)} C_{6-m}^{v(t, f)-v} C_{m}^{v} n_{1}^{[v(t, f)-v]} \\
& \times n_{2}^{[6-m-v(t, f)+v]}\left(1-n_{1}\right)^{v}\left(1-n_{2}\right)^{m-v},
\end{aligned}
$$

где $n_{1}=y-(2 t-1) \eta / 2 t$ и $n_{2}=y+\eta / 2 t-$ вероятности обнаружения атома углерода на узле вакансионной и углеродной подрешеток соответственно при образовании сверхструктуры типа $M_{2 t} \mathrm{C}_{2 t-1} ; g_{f}$ - мультиплетность неэквивалентных позиций металлических атомов, находящихся в центре каждого кластера $\left(\Sigma_{f} g_{f}=\Phi\right)$; $v(t, f)$ - число узлов вакансионной подрешетки, принадлежащих кластеру с мультиплетностью $g_{f}$ в сверхструктуре типа $M_{2 t} \mathrm{C}_{2 t-1}$.

Используя уравнения (1), (3) и (4), можно найти объем кристалла и, соответственно, период базисной решетки $a_{B 1}$ нестехиометрического карбида $\mathrm{VC}_{y} \mathrm{c}$ любой степенью порядка $\eta$. В упорядоченном карбиде величина $\eta$ может изменяться от $\eta_{\text {trans }}$ (значение параметра порядка в точке перехода) до $\eta_{\max }$, поэтому период $a_{B 1}$ упорядоченного карбида можно рассчитать для этих двух предельных случаев.

Согласно $[13,14]$ зависимости $\eta_{\max }$ и $\eta_{\text {trans }}$ от состава карбида $M C_{y}$ при образовании упорядоченной фазы типа $M_{2 t} \mathrm{C}_{2 t-1}$ без учета ее границ имеют вид

$$
\eta_{\max }(y)=\left\{\begin{array}{lll}
2 t(1-y), & \text { если } & y>(2 t-1) / 2 t \\
2 t y /(2 t-1), & \text { если } & y<(2 t-1) / 2 t
\end{array}\right.
$$

и

$\left(\eta_{\text {trans }} / 2\right)\left[\partial S_{\mathrm{c}}(y, \eta) / \partial \eta\right]_{\eta=\eta_{\text {trans }}}-S_{\mathrm{c}}\left(y, \eta_{\text {trans }}\right)+S_{\mathrm{c}}(y, 0)=0$,

где конфигурационная энтропия $S_{\mathrm{c}}(y, \eta)$ равна

$$
\begin{aligned}
S_{\mathrm{c}}(y, \eta)= & -\left(k_{\mathrm{B}} / 2 t\right)\left\{n_{1} \ln n_{1}+\left(1-n_{1}\right) \ln \left(1-n_{1}\right)\right. \\
& \left.+(2 t-1)\left[n_{2} \ln n_{2}+\left(1-n_{2}\right) \ln \left(1-n_{2}\right)\right]\right\} .
\end{aligned}
$$

Области гомогенности упорядоченных фаз $M_{2 t} \mathrm{C}_{2 t-1}$ ограничены нижней $y_{\text {lower }}$ и верхней $u_{\text {upper }}$ границами. На границах области гомогенности параметр дальнего порядка обращается в ноль, а максимальная величина $\eta$ может быть достигнута для стехиометрического состава $y_{\mathrm{st}}=(2 t-1) / 2 t$ упорядоченной фазы. Это можно учесть, представив зависимость параметра дальнего порядка $\eta_{\mathrm{b}}$ от состава $y$ упорядоченной фазы как

$\eta_{\mathrm{b}}=\left\{\begin{array}{l}\eta_{\text {id }}\left(y-y_{\text {lower }}\right) /\left(y_{\text {st }}-y_{\text {lower }}\right), \text { если } \quad y_{\text {st }} \geq y \geq y_{\text {lower }} \\ \eta_{\text {id }}\left(y-y_{\text {upper }}\right) /\left(y_{\text {st }}-y_{\text {upper }}\right), \\ \text { если } \quad y_{\text {st }} \leq y \leq y_{\text {upper }}\end{array}\right.$,

где $\eta_{\text {id }}(y)$ - зависимость максимального или равновесного параметра дальнего порядка для сверхструктуры $M_{2 t} \mathrm{C}_{2 t-1}$ от ее состава $y$, рассчитанная без учета границ области гомогенности по формулам (5) или (6) соответственно.

Фаза $\mathrm{V}_{6} \mathrm{C}_{5}$ имеет область гомогенности от $\mathrm{VC}_{0.75}$ до $\mathrm{VC}_{0.845}[13,18,20]$, фаза $\mathrm{V}_{8} \mathrm{C}_{7}$ имеет очень узкую область гомогенности от $\mathrm{VC}_{0.871}\left(\mathrm{~V}_{8} \mathrm{C}_{6.97}\right)$ до $\mathrm{VC}_{0.877}$ $\left(\mathrm{V}_{8} \mathrm{C}_{7.02}\right)$ [26].

В первом варианте расчета предполагалось, что в нестехиометрическом карбиде ванадия $\mathrm{VC}_{y}$ достигнута максимальная степень дальнего порядка $\eta_{\mathrm{b}-\max }$. Во втором варианте расчета предполагалось, что в упорядоченном карбиде параметр дальнего порядка имеет такую же величину, как при температуре фазового перехода беспорядок-порядок $T_{\text {trans }}$, т. е. $\eta_{\mathrm{b} \text {-trans }}$.

Рассчитанные изменения периода базисной решетки $a_{B 1}$ неупорядоченного карбида ванадия $\mathrm{VC}_{y}$ и упорядоченных фаз $\mathrm{V}_{6} \mathrm{C}_{5}$ и $\mathrm{V}_{8} \mathrm{C}_{7}$ в их областях гомогенности показаны на рис. 4. Видно, что упорядочение сопровождается некоторым ростом периода $a_{B 1}$ по сравнению с неупорядоченным карбидом. Сравнение результатов расчета с литературными данными по периоду базисной 


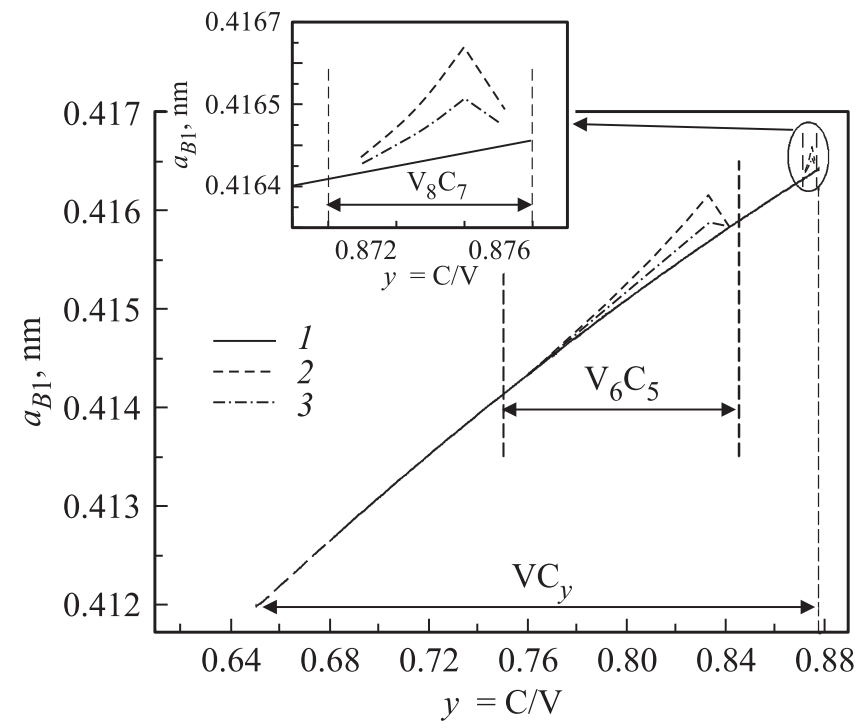

Pис. 4. Зависимости периода базисной кубической решетки $a_{B 1}$ от состава карбида ванадия $\mathrm{VC}_{y}$ в неупорядоченном (1) и упорядоченных $(2,3)$ состояниях при температуре $300 \mathrm{~K}$. 2 - расчет в приближении максимальной степени дальнего порядка $\eta_{\text {b-max }}$ в упорядоченных фазах, 3 - расчет в приближении степени дальнего порядка, равной параметру дальнего порядка при температуре фазового перехода беспорядок-порядок $T_{\text {trans }}$, т. е. $\eta_{\text {b-trans. }}$ Границы областей гомогенности фаз $\mathrm{VC}_{y}, \mathrm{~V}_{6} \mathrm{C}_{5}$ и $\mathrm{V}_{8} \mathrm{C}_{7}$ показаны вертикальными пунктирными линиями.

решетки $a_{B 1}$ упорядоченных фаз $\mathrm{V}_{6} \mathrm{C}_{5} \quad[17,18,20]$ и $\mathrm{V}_{8} \mathrm{C}_{7}[16,19]$ показало, что к экспериментальным значениям $a_{B 1}$ наиболее близки значения периода, рассчитан-

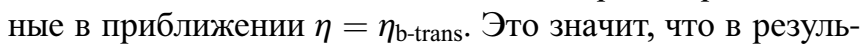
тате отжига в нестехиометрическом карбиде ванадия достигается степень дальнего порядка, соответствующая термодинамически равновесному распределению атомов углерода и вакансий в решетке.

Рентгеновское и нейтронографическое исследования $[26,27]$ упорядоченной фазы $\mathrm{V}_{8} \mathrm{C}_{7}$ показали, что атомы V, образующие октаэдрическое окружение вакантных узлов $\square$ неметаллической подрешетки, смещены по направлению к вакансии. Если в неупорядоченном карбиде $\mathrm{VC}_{y}$ атомы $\mathrm{V}$ тоже смещаются $\mathrm{\kappa}$ вакансии, то рост концентрации вакантных междоузлий $\square \mathrm{V}_{6}$, имеющих меньший линейный размер по сравнению с заполненными октаэдрическими междоузлиями $\mathrm{CV}_{6}$, должен сопровождаться уменьшением периода $a_{B 1}$. Действительно, увеличение концентрации вакансий (или уменьшение концентрации атомов углерода) сопровождается наблюдаемым уменьшением периода решетки неупорядоченного карбида ванадия $\mathrm{VC}_{y}$.

В последние годы основное внимание обращено на получение и применение нанокристаллических порошков карбида ванадия [9,10,28-30]. Как правило, синтезированные нанопорошки аттестуют по составу и кристаллической структуре путем сравнения экспериментальных данных по рентгеновской дифракции со стандартными дифракционными данными фазы $\mathrm{V}_{8} \mathrm{C}_{7}$ без полнопрофильного уточнения структуры $[9,10]$. Однако в работах $[9,10]$ нет никаких доказательств наличия сверхструктуры $\mathrm{V}_{8} \mathrm{C}_{7}$ в синтезированных образцах карбида ванадия, а наблюдаемые дифракционные отражения принадлежат не фазе $\mathrm{V}_{8} \mathrm{C}_{7}$, а неупорядоченному кубическому карбиду $\mathrm{VC}_{y}, y \sim 0.88$.

Другой неудачный способ аттестации нанопорошков карбида ванадия - сравнение периода решетки с концентрационной зависимостью периода решетки крупнозернистого (bulk) карбида ванадия $\mathrm{VC}_{y}$. Это тоже совершенно неправильно, так как нанопорошки имеют чрезвычайно большую удельную поверхность и обладают высокой химической активностью по отношению к пара́м воды и газовым примесям, особенно к кислороду. Нанопорошки карбида ванадия химически более активны, чем нанопорошки других карбидов с таким же средним размером частиц. Хранение нанопорошков карбида ванадия на воздухе приводит к их быстрому, в течение $1-2 \mathrm{~h}$, загрязнению и окислению кислородом, а также к поверхностной адсорбции воды. В наших предшествующих работах $[27,31,32]$ было показано, что содержание примесного кислорода в нанопорошках карбида ванадия со средним размером частиц менее $80-100 \mathrm{~nm}$ достигает $\sim 3 \mathrm{wt} . \%$, содержание физически адсорбированной воды составляет от 2 до $8 \mathrm{wt} . \%$. Период кристаллической решетки таких нанопорошков существенно отличается от такового для крупнозернистого (bulk) карбида ванадия $\mathrm{VC}_{y}$ и не может служить надежной характеристикой их состава.

Таким образом, изучение и применение нанокристаллических порошков карбида ванадия требует их тщательной всесторонней аттестации по химическому составу, содержанию примесей и параметрам кристаллической структуры.

\section{4. Заключение}

Уменьшение периода решетки карбида ванадия $\mathrm{VC}_{y}$ в области гомогенности неупорядоченной фазы при уменьшении содержания углерода (или увеличении концентрации структурных вакансий) обусловлено смещением атомов ванадия по направлению к вакансии, аналогичном таковому смещению в упорядоченной фазе $\mathrm{V}_{8} \mathrm{C}_{7}$. Упорядочение карбида ванадия $\mathrm{VC}_{y}$ с образованием сверхструктур $\mathrm{V}_{6} \mathrm{C}_{5}$ и $\mathrm{V}_{8} \mathrm{C}_{7}$ приводит к росту периода базисной кристаллической решетки по сравнению с неупорядоченным карбидом.

\section{Список литературы}

[1] H.J. Goldschmidt. Interstitial Alloys. Plenum Press, N.Y. (1967). $820 \mathrm{p}$.

[2] R. Kesri, S. Hamar-Thibault. Acta Met. 36, 1, 149 (1988).

[3] T.N. Baker. Mater. Sci. Techn. 25, 9, 1083 (2009). 
[4] Z.Z. Fang, X. Wang, T. Ryu, K.S. Hwang, H.Y. Sohn. Int. J. Refr. Met. Hard Mater. 27, 2, 288 (2009).

[5] J. Poetschke, V. Richter, R. Holke. Int. J. Refr. Met. Hard Mater. 31, 218 (2012).

[6] A.S. Kurlov, A.I. Gusev. Tungsten Carbides: Structure, Properties and Application in Hardmetals. Springer, ChamHeidelberg-N. Y.-Dordrecht-London (2013). 256 p.

[7] А.С. Курлов, А.И. Гусев. Физика и химия карбидов вольфрама. Физматлит, М. (2013). 272 с.

[8] J.M. Marshall, A. Kusoffsky. Int. J. Refr. Met. Hard Mater. 40, 23 (2013).

[9] Z. Hu, C. Chen, H. Meng, R. Wang, P.K. Shen, H. Fu. Electrochem. Commun. 13, 763 (2011).

[10] Z. Yan., M. Zhang, J. Xie, P.K. Shen. J. Power Source 243, 336 (2013).

[11] T. Huang, J. Yu, J. Han, Z. Zhang, Y. Xing, C. Wen, X. Wu, Y. Zhang. J. Power Source 300, 483 (2015).

[12] J. Yu, X. Gao, G. Chen, X. Yuan. Int. J. Hydrogen Energy 41, 4150 (2016).

[13] A.I. Gusev, A.A. Rempel, A.J. Magerl. Disorder and Order in Strongly Nonstoichiometric Compounds: Transition Metal Carbides, Nitrides and Oxides. Springer, Berlin-HeidelbergN. Y.-London. (2001). 607 p.

[14] А.И. Гусев. Нестехиометрия, беспорядок, ближний и дальний порядок в твердом теле. Физматлит, М. (2007). 856 с.

[15] А.И. Гусев. ЖФХ 74, 600 (2000).

[16] T. Athanassiadis, N. Lorenzelli, C.H. de Novion. Ann. Chum. France 12, 2, 129 (1987).

[17] V.N. Lipatnikov, P. Ettmayer. In: Proc. of the Intern. Plansee Seminar / Eds G. Kneringer, P. Rodhammer, P. Wilhartitz. Plansee Group, Reutte Austria (1997). V. 2. P. 485-497.

[18] V.N. Lipatnikov, W. Lengauer, P. Ettmayer, E. Keil, G. Groboth, E. Kny. J. Alloys Comp. 261, 192 (1997).

[19] D. Rafaja, W. Lengauer, P. Ettmayer, V.N. Lipatnikov. J. Alloys Comp. 269, 60 (1998).

[20] V.N. Lipatnikov, A.I. Gusev, P. Ettmayer, W. Lengauer. J. Phys.: Condens. Matter 11, 1, 163 (1999).

[21] В.Н. Липатников, А.И. Гусев, П. Эттмайер, В. Ленгауэр. ФТT 41, 529 (1999).

[22] L. Ramqvist. Jernkontorets Annaler 152, 9, 467 (1968).

[23] А.С. Борухович, Н.М. Волкова. Изв. АН СССР. Неорган. материалы 7, 9, 1529 (1971).

[24] Н.М. Волкова, П.В. Гельд. Труды Института химии УФАН СССР. Вып. 14, 41-46 (1967).

[25] X'Pert HighScore Plus. Version 2.2e (2.2.5). () 2009 PANalytical B. V., Almelo, The Netherlands.

[26] А.И. Гусев, А.С. Курлов, А.А. Ремпель. Письма в ЖЭТФ 101, 8, 589 (2015).

[27] А.И. Гусев, А.С. Курлов, И.А. Бобриков, А.М. Балагуров. Письма в ЖЭТФ 102, 3, 179 (2015).

[28] J. Ma, M. Wu, Y. Du, S. Chen, J. Ye, L. Jin. Mater. Lett. 63, 11, 905 (2009).

[29] Z. Zhao, H. Zuo, Y. Liu, W.Q. Song, S.F. Mao, Y.R. Wang. Int. J. Refr. Met. Hard Mater. 27, 6, 971 (2009).

[30] M. Mahajan, K. Singh, O.P. Pandey. Int. J. Refr. Met. Hard Mater. 36, 106 (2013).

[31] А.А. Ремпель, А.И. Гусев. Письма в ЖЭТФ 69, 6, 436 (1999).

[32] A.S. Kurlov, A.I. Gusev, E.Yu. Gerasimov, I.A. Bobrikov, A.M. Balagurov, A.A. Rempel. Superlatt. Microstr. 90, 148 (2016). 